
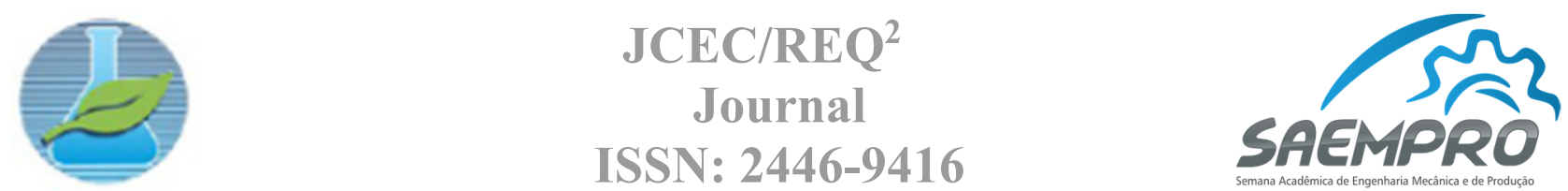

\author{
"EU, A INDÚSTRIA E O MUNDO" \\ 08 a 11 de novembro de 2016 no campus Vicosa da UFV \\ Departamento de Engenharia de Produção e Mecânica - DEP \\ Universidade Federal de Viçosa - UFV
}

\title{
SISTEMA DE GESTÃO DE DESENVOLVIMENTO DE PRODUTO PARA UMA EQUIPE DE COMPETIÇÃO DO FÓRMULA SAE
}

\author{
Anna Laura Teixeira de Almeida, Lucas Benini \\ Universidade Federal de Viçosa - Departamento de Engenharia de Produção e Mecânica \\ Avenida Peter Henry Rolfs, s/n - Campus Universitário - 36570-900 - Viçosa - MG \\ annalauraufv@gmail.com, lucas.benini@ufv.br
}

\section{INTRODUÇÃO}

Este trabalho trata do processo de elaboração do modelo de referência de um Sistema de Gestão do Desenvolvimento de Produtos (SGDP) para uma equipe de estudantes de Engenharias da Universidade Federal de Viçosa (UFV) que objetiva participar da competição Fórmula SAE Brasil. A categoria de competição universitária Fórmula SAE, criada pela Society of Automotive Engineering (SAE) em 1980 nos EUA e em 2004 no Brasil, tem por objetivo avaliar o projeto e desempenho de um veículo protótipo tipo fórmula, monoposto e openwheels construído e projetado por graduandos em engenharia, conforme padrões e normas de segurança definidas no regulamento da competição.

Para fins da competição, os estudantes devem supor que um grupo de investidores de uma empresa de manufatura os contratou para desenvolver um protótipo de carro de corrida que será avaliado para sua possível produção, cujo mercado alvo é o de competição não profissional. Dessa forma, o veículo deve ter alto desempenho em aceleração, frenagem e manobrabilidade, deve ser de baixo custo, de fácil manutenção e seguro ao usuário. Em termos de manufatura, o projeto de fabricação deve ser capaz de produzir 4 unidades por dia, com um custo de produção limitado. $\mathrm{O}$ desafio para cada equipe é projetar e fabricar um carro que melhor atenda a esses objetivos.

A equipe da UFV, ainda em processo de oficialização pela instituição, foi criada em outubro de 2015 e é intitulada de "Majorados UFV". Por ser uma equipe nova e de forma a poder superar a complexidade do projeto, o orçamento elevado, o curto time to market (a competição é anual) e a alta competitividade desta categoria, a "Majorados UFV" tem buscado abordar uma postura empresarial, o que corrobora o objetivo geral do Fórmula SAE. Para tanto, a equipe identificou a necessidade de sistematizar o processo de desenvolvimento dos veículos de forma a identificar ações que devem ser realizadas em uma ordem lógica pré-estabelecida. A lógica do SGDP é desenvolver produtos e seus processos de obtenção (produção ou operações), com qualidade e de maneira eficiente, com o mínimo de retrabalho e desperdício de recursos, através do estabelecimento de fases e atividades, segundo um modelo de referência que auxilie no atendimento do objetivo da competição de maneira eficaz.

\section{METODOLOGIA}

De modo geral, desenvolver produtos consiste em um conjunto de atividades por meio das quais busca-se chegar a especificações de projeto de um produto e de seu processo de produção, para que a manufatura seja capaz de produzi-lo (Rosenfeld et al., 2006). Na literatura são propostas diversas metodologias para o desenvolvimento de novos produtos, no entanto, cabe à empresa ou organização encontrar e adequar aquela que melhor se adapte à sua realidade e cultura. Um estudo mais elaborado e eficaz sobre a metodologia do desenvolvimento de produto se faz necessário para que se possa 
reduzir os riscos, retrabalhos e os intervalos que compõem esta atividade (Montgomery \& Porter, 1998).

A equipe "Majorados UFV" tem se baseado em três metodologias chave para elaboração do seu Sistema de Gestão de Desenvolvimento de Produtos (SGDP): Processo de Desenvolvimento de Produto (PDP) proposto por Rosenfeld et al. (2006), Quality Function Deployment (QFD) de Cheng \& Filho (2007) e no One Global Product Develepment System (GPDS) desenvolvida pela Ford Motor Company (2005).

O modelo de PDP proposto por Rosenfeld et al. (2006) é voltado para empresas de manufatura de bens de consumo duráveis e de capital. Este modelo é formado por macrofases, subdividas em fases e atividades. As três macrofases são: Pré-desenvolvimento, Desenvolvimento e Pósdesenvolvimento. A primeira macrofase envolve o Planejamento Estratégico dos Produtos e o Planejamento do Projeto, onde são definidos quais produtos serão desenvolvidos e é realizado o escopo para cada produto e projeto, definindo os recursos necessários, tempo e estimativa de custo. Se o planejamento for aprovado, passa-se para a macrofase seguinte. A segunda macrofase enfatiza os aspectos tecnológicos correspondentes à definição do produto em si, suas características e forma de produção. Esta macrofase é formada pelas fases Projeto Informacional, Projeto Conceitual, Projeto Detalhado e Preparação para a Produção, culminando no lançamento do produto. A terceira macrofase, Pós-desenvolvimento, inicia-se com a produção e comercialização do produto, acompanhamento do ciclo de vida e acaba quando decide-se descontinuar o produto do mercado.

O modelo proposto por Cheng \& Filho (2007) foi criado na década de 60 pelo japonês Yoji Akao. É um método utilizado para o desenvolvimento de produtos focado na satisfação dos clientes e se orienta sob o seguinte pressuposto: "todo produto/serviço terá sucesso se, somente se, os clientes ficarem satisfeitos com o produto desenvolvido". Sendo assim, o método tem como objetivo principal permitir que a equipe de desenvolvimento do produto incorpore as reais necessidades do cliente em seus projetos, traduzindo a voz do cliente em especificações técnicas de engenharia para o projeto. O método QFD pode ser subdividido em desdobramento da qualidade (QD) e desdobramento da função qualidade no sentido restrito (QFDR). O desdobramento da qualidade (QD) pode ser conceituado como o processo que tem em vista: buscar e traduzir as exigências dos clientes em características da qualidade do produto por intermédio de desdobramentos sistemáticos, iniciando-se com a determinação da voz do cliente, passando pelo estabelecimento de funções, mecanismos, componente, processos, matéria-prima e estendendo-se até o estabelecimento dos parâmetros de controle dos processos. O desdobramento da função qualidade no sentido restrito (QFDR) é também conhecido como desdobramento da função trabalho e seu objetivo é especificar com precisão, quais funções ou trabalhos humanos são necessários para obter a qualidade do produto e da empresa que satisfaçam as necessidades dos clientes.

O One Global Product Development System (GPDS) é o modelo de desenvolvimento de produtos elaborado e utilizado na Ford, lançado em 2005. O GPDS é a reunião dos melhores métodos de criação de produtos de todas as operações globais da empresa Ford Motor e hoje é utilizado em todas as unidades da empresa como uma "receita de bolo", porém para carros. O GPDS é atualizado continuamente com as últimas lições aprendidas à medida que se desenvolve novos produtos. Este modelo fornece um conjunto comum de metas e métricas para o desenvolvimento de todos os programas de veículos, o que aumenta a eficiência e qualidade, possibilitando à Ford desenvolver produtos de maneira mais rápida, mais competitiva e com maior margem de contribuição para $\mathrm{o}$ crescimento do lucro. Vale ressaltar que a metodologia desenvolvida pela Ford não está explicitamente publicada na internet, poucas informações estão disponíveis. A equipe "Majorados UFV" tem buscado informações de maneira primária através de entrevistas com engenheiros da Ford de forma a conhecer melhor o processo de gestão do desenvolvimento de produtos utilizado na montadora.

O modelo desenvolvido para a equipe buscou abordar as seguintes funções encontradas nos modelos abordados na metodologia, conforme Tab. 1: 
Tabela 1 - Funções na literatura a serem incorporadas no SGDP.

\begin{tabular}{l|c|c|c}
\hline & PDP & QFD & GPDS \\
\hline Delimitar o sistema em macrofases, fases e atividades & $\mathrm{X}$ & & \\
\hline Determinar cronograma & $\mathrm{X}$ & & \\
\hline Determinar gates de decisão entre fases e macrofases & $\mathrm{X}$ & & \\
\hline Desenvolver veículos que atendam aos requisitos da competição & & $\mathrm{X}$ & \\
\hline Desenvolver veículos que atendam ao mercado-alvo & & $\mathrm{X}$ & \\
\hline Desenvolver tabelas e matrizes para desdobrar o projeto & & $\mathrm{X}$ & \\
\hline Garantir que o desenvolvimento esteja de acordo com as especificações & & $\mathrm{X}$ & \\
\hline Incorporar no modelo práticas utilizadas em empresas automobilísticas & & & $\mathrm{X}$ \\
\hline Buscar a melhoria contínua do modelo & & & $\mathrm{X}$ \\
\hline
\end{tabular}

\section{RESULTADOS}

O SGDP elaborado para a equipe "Majorados UFV" ficou definido em três macrofases: Prédesenvolvimento, Desenvolvimento e Pós-desenvolvimento. Na Fig. 1 está ilustrado o modelo, onde contém as macrofases e abaixo destas estão as fases que as compõem. Entre cada macrofase e fases há um gate de decisão (losangos vermelhos) que é a avaliação dos resultados, marco importante de reflexão sobre o andamento do projeto, antecipando problemas e gerando aprendizado para a equipe. Trata-se de uma revisão ampla e minuciosa, considerando a qualidade dos resultados concretos obtidos, a situação diante do planejamento e o impacto dos problemas encontrados. No modelo, só se avança de uma (macro)fase para outra após passar pelos gates.

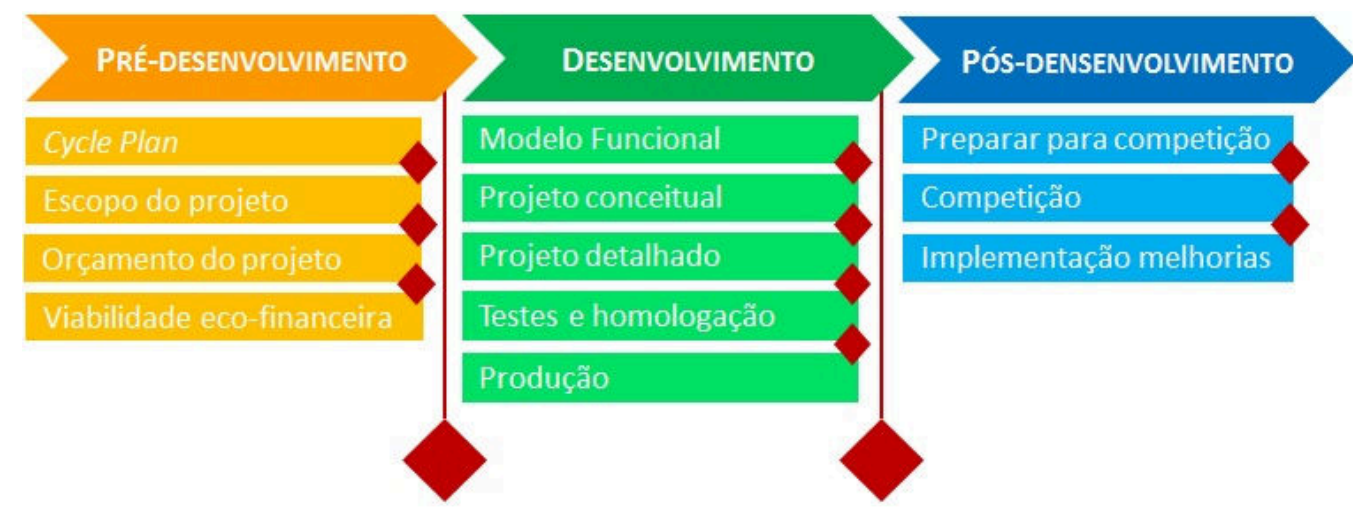

Figura 1 - Modelo do SGDP elaborado para a equipe "Majorados UFV".

A Fig. 1 não abrange as atividades de cada fase, que são o detalhamento de execução do modelo. As atividades são bem específicas e pontuais e incluem pontos das metodologias utilizadas como base para o modelo. A proposta do modelo é que ele seja cíclico, ou seja, repetindo-se a cada período de 12 meses, dando início ao desenvolvimento do veículo para a próxima competição. Espera-se que com a implementação do SGDP a equipe consiga atingir seu objetivo de performance na competição.

\section{REFERÊNCIAS}

ROZENFELD, H.; FORCELLINI, F.A.; AMARAL, D.C.; TOLEDO, J.C.; SILVA, S.L.; ALLIPRANDINI, D.H.; SCALICE, R.K. "Gestão de Desenvolvimento de Produtos: uma referência para a melhoria do processo". São Paulo: Saraiva, 2006.

MONTGOMERY, Cynthia A.; PORTER, Michael E. "Estratégia: a busca da vantagem da vantagem competitiva”. Rio de Janeiro: Campus, 1998. 